\title{
Life Cycle Assessment of Waste Management: Are We Addressing the Key Challenges Ahead of Us?
}

Astrup, Thomas Fruergaard; Pivnenko, Kostyantyn; Eriksen, Marie Kampmann; Boldrin, Alessio

Published in:

Journal of Industrial Ecology

Link to article, DOI:

10.1111/jiec.12811

Publication date:

2018

Document Version

Peer reviewed version

Link back to DTU Orbit

Citation $(A P A)$ :

Astrup, T. F., Pivnenko, K., Eriksen, M. K., \& Boldrin, A. (2018). Life Cycle Assessment of Waste Management: Are We Addressing the Key Challenges Ahead of Us? Journal of Industrial Ecology, 22(5), 1000-1004. https://doi.org/10.1111/jiec.12811

\section{General rights}

Copyright and moral rights for the publications made accessible in the public portal are retained by the authors and/or other copyright owners and it is a condition of accessing publications that users recognise and abide by the legal requirements associated with these rights.

- Users may download and print one copy of any publication from the public portal for the purpose of private study or research.

- You may not further distribute the material or use it for any profit-making activity or commercial gain

- You may freely distribute the URL identifying the publication in the public portal 


\title{
Life Cycle Assessment of Waste Management: Are We Addressing the Key Challenges Ahead of Us?
}

\author{
A Special Feature \\ Thomas Fruergaard Astrup, Kostyantyn Pivnenko, Marie Kampmann Eriksen and Alessio Boldrin \\ Department of Environmental Engineering, Technical University of Denmark, Kgs. Lyngby, Denmark
}

[Pull-quote: the environmental benefits quantified in waste LCA studies are often directly proportional to the amounts of waste materials routed to a particular recycling technology, whereas the specific composition, properties and presence of targeted resources in the waste materials may not be fully addressed. This suggests that the actual efforts associated with recovering and recycling of resources in waste may not be fully reflected by current LCA modeling approaches.]

Within the last decade, life cycle assessment (LCA) of waste management solutions has come a very long way. From a situation in which the establishment and evaluation of individual technology scenarios was in itself a major achievement (e.g., Abeliotis et al. 2012; Bergsdal et al. 2005; Cadena et al. 2009) to the current much more mature level in which extensive and integrated scenarios are evaluated in view of uncertainties, methodological implications, and detailed framework conditions (e.g., Ripa et al. 2017; Tonini et al. 2018). While this development may reflect attempts to more accurately model waste management solutions, the current level also illustrates the complexities associated with environmental LCA of waste management systems. Looking ahead, however, the key questions are: which are the most eminent challenges that should be tackled? And how do current studies address these challenges?

The current political focus on material recycling and circular economy represents an important backdrop setting for waste LCA studies. Within industrial ecology, however, these concepts far from represent novel thinking. Resource efficiency, recovery and recycling as well as closing of material loops have been on the agenda at least since the seminal article by Frosch and Gallopoulos (1989) that is said to have launched the field. Regardless of the specific terminology applied, material recycling is receiving considerable attention by media, decision-makers and researchers alike (European Council 2018; Ellen MacArthur Foundation 2013; EEA 2011). The European Union has recently decided to increase recycling targets for a range of waste material fractions and at the same time attempts to reduce the ambiguity in recycling rate calculations (EC 2015a; European Council 2018). Both initiatives increase the demands for 
documentation of benefits from recycling and add pressure on stakeholders within the recycling chain. While the overall intention is to minimize dependence on raw material import, increase resource efficiency as well as innovation and job creation, these policies also intend to improve the overall environmental performance of society over a wide range of impact categories (EC 2015b). Though numerous studies in literature have demonstrated that material recycling is environmentally beneficial (e.g., Villanueva and Wenzel 2007; WRAP 2010), challenges exist in relation to the specific implementation of the European policies and in particular the selection of individual processing and recycling chains over others (Vadenbo et al. 2014). The ability of LCA to provide consistent assessments, however, also represents an opportunity for waste LCA studies to provide tangible inputs into policy-making.

Providing meaningful inputs to decision-makers calls for responsibility. It is well-established that many existing waste LCA studies fail at providing even the most basic documentation about goal and scope, framework conditions, technology inventory data, and assessment assumptions in general (Laurent et al. 2014; Astrup et al., 2015). The results from such studies are at best opaque, but may easily be biased. In a regulatory transition period with society moving towards more material recycling, it is imperative that waste LCA studies reflect state-of-the-art approaches, offer well-documented results, show awareness of the methodological challenges associated with LCA of waste systems and are accompanied with transparent discussions on weaknesses and uncertainties. Although this is demanding, the alternative is hardly useful.

This special feature contains a collection of articles that pinpoint a range of methodological challenges and provide examples of how to address them within waste LCA studies. This editorial outlines the most critical methodological aspects and highlights key perspectives from the individual studies.

\section{Which are the Challenges?}

A specific challenge in relation to material recycling and policy implementation is the traditional regulatory focus on waste amounts, rather than environmental performance of a waste solution (EC 2015b). In a circular economy perspective, this could mean that simple use of waste materials for new purposes (assuming regulatory acceptance) may be prioritized over the solution providing the largest environmental benefits, e.g. if the recycled material displaces materials of low quality or does not displace virgin material at all, the overall environmental benefits from recycling are minor if at all present (Sevigné-Itoiz et al. 2015; Zink and Geyer 2017). While LCA offers a methodology that may address precisely this conflict, waste LCA studies also struggle with finding the right approach to reflect resource quality and displacement, rather than merely relying on material quantities (Vadenbo et al. 2017; Zink et al. 2016). In other words, the environmental benefits quantified in waste LCA studies are often directly proportional to the amounts of 
waste materials routed to a particular recycling technology, whereas the specific composition, properties and presence of targeted resources in the waste materials may not be fully addressed (e.g., Rigamonti et al. 2009b; Zink et al. 2016; Rigamonti et al. 2009a; Shen et al. 2010). This suggests that the actual efforts associated with recovering and recycling of resources in waste may not be fully reflected by current LCA modeling approaches.

Another critical aspect is availability and quality of the inventory data describing the involved waste technologies and processes. Waste management is characterized by activities representing impacts to the environment, while the environmental benefits from resource recovery activities generally occur downstream of the waste system itself through displacement of other products and services (Vadenbo et al. 2017). As such, in-depth knowledge of the involved waste conversion and treatment processes, the emissions and properties of the outputs from these processes, the relevant technology configurations and associated performances are all required to appropriately model the waste management system. To provide a balanced assessment, however, similar knowledge is needed also for the alternative management of the waste in question. This means that robust inventory data for a wide range of waste technologies are needed for state-of-the-art LCA studies involving municipal solid waste, regardless of whether the goal of a study focuses on a specific circular economy solution. This aspect has, however, often been overlooked in waste LCA studies.

Assuming that a relevant range of technology inventory data is available, ensuring appropriate selection and representation of the study goal and scope is not necessarily trivial (Brogaard et al. 2014). Traditional waste management involves a range of archetype processes, e.g. waste collection, mechanical sorting, biological and thermal treatment and conversion, recycling and landfilling. However, within each process type a wide range of technology configurations are possible, partly depending on the geographical and temporal scope, but also depending on the technology level itself. While existing inventory datasets do not fully reflect the variety of technology options, an LCA study nevertheless involves - implicitly or not selection among technology configurations. Obviously, this selection should appropriately reflect the scope of the study. Particularly for waste systems, these choices may be critical as the foreground waste system represents the main environmental impacts, as previously indicated. Again this aspect is often overlooked by waste LCA studies (e.g., Astrup et al. 2015).

Waste prevention - i.e. reuse, source reduction, and cleaner waste materials - is possibly the most important challenge of them all, both in context of LCA but also in society itself. Prevention effects are inherently difficult to quantify and regulate; in many countries this has resulted in somewhat limited attention from regulatory agencies (RECREATE 2017). While this may gradually change in Europe with the current legislative focus (EC 2015b), the regulatory implications go beyond the waste management system 
itself: products need to be designed to avoid waste generation. As waste LCA studies typically apply a zeroburden assumption, in which the upstream environmental impacts associated with production, distribution, and use phases of materials in the waste are excluded from the system boundaries, evaluating environmental benefits from waste prevention is not straightforward. Typically, the environmental impacts found upstream from the waste system by far outweigh the impacts represented by waste management and the savings from downstream recycling (e.g., Dormer et al. 2013). So far only few attempts have been made in literature to address this topic (e.g., Gentil et al. 2011; Dolci et al. 2016; Nessi et al. 2012).

Summarizing the above, this special feature focuses on the following five aspects related to LCA of waste management systems:

1) Representation of the environmental benefits associated with recycling and selection of impact indicator types (Ortego et al. 2018);

2) Providing systematic technology inventory data for representation of variabilities in technology implementation (Beylot et al. 2017);

3) Application of experimental data as basis for environmental assessment of waste management (Capobianco et al. 2017);

4) Selection of technology data for appropriate representation of goal and scope of LCA studies (Henriksen et al. 2017);

5) Quantification and communication of environmental benefits from waste prevention (Hutner et al., 2018)

The above studies were all presented at the $1^{\text {st }}$ International Conference on Life Cycle Assessment of Waste held in Cetraro, Italy, in 2016. The second iteration of the conference in 2018 was held in Copenhagen, Denmark, for details please refer to www.wasteLCA.org.

\section{Sustainability Assessment using Thermodynamic Rarity}

Based on a case representing resource recovery from end-of-life vehicles (ELVs), Ortego et al. (2018) apply thermodynamic rarity as metric to illustrate the potential benefits of resource recovery and recycling. This is done by estimating the embedded exergy costs (rarity) of selected critical metals present in four different ELV types (conventional and electrified vehicles). By comparing recycled mass with thermodynamic rarity, a potential "hidden value" of critical metals is identified. Ortego et al. (2018) highlight that current recycling targets may fail in increasing recycling of critical metals in vehicles when solely based on mass. Thermodynamic rarity is found to be a useful metric that may be used both by regulators and automobile 
manufacturers in the design phase. The study identifies a range of specific metals with insignificant weight contributions to ELV recycling (i.e., $\mathrm{Mo}, \mathrm{Co}, \mathrm{Nb}$, and $\mathrm{Ni}$ ), but with more prominent importance as measured by thermodynamic rarity.

\section{Waste Incineration Inventory Data}

Beylot et al. (2017) provide an elaborate dataset for 90 French municipal solid waste incinerators covering the period of 2012-2015. The study addresses variations in technology configurations, energy efficiencies, consumption of reagents for flue gas cleaning and process-specific air emissions. The data are provided as a basis for future LCA studies of waste management in France and illustrates the rather extensive efforts that are ideally required as basis for a national level LCA of waste management. The study further identifies a range of reagent consumptions and air emissions that are significantly affected by the investigated technology configurations.

\section{Application of Experimentally-based Emission Data}

With an example of soil utilization for regeneration of brownfield sites (e.g., urban and abandoned areas characterized by debris and various levels of contamination from previous activities), Capobianco et al. (2017) illustrate how analytical data from lab experiments are applied to estimate environmental emissions within an LCA. Based on leaching data for selected brownfield soils and stabilization/solidification processes, the performance of soil regeneration is evaluated relative to traditional landfilling of the soils. The study demonstrates that while the soil treatment may be environmentally preferable to landfilling for some impact categories, the cement binder added in the treatment process is found to be critical for the overall environmental performance of the regeneration solution. In contrast, the leaching data obtained from the lab experiments are found not to be decisive for the LCA results.

\section{Links Between Technology Data and Assessment Scope}

The importance of data selection and compliance with the study scope is further highlighted by Henriksen et al. (2017). With landfilling as illustrative technology case, the study investigates the importance of technology configuration and inventory data modeling relative to the context and scope of an LCA study. By evaluating 52 discrete landfill technology configurations and datasets (e.g., landfill type, regional conditions, leachate and landfill gas management), the study demonstrates that inventory modeling has profound effects on the LCA results. Common examples of selecting site-specific inventory data for representation of an average, non-specific location, or use of aggregated data for representation of a site- 
specific case study, are in both cases demonstrated as providing biased results that may not be aligned with the study scope.

\section{Assessment of Waste Prevention and Communication of Results}

Hutner et al. (2018) assesses waste prevention measures through a community-based approach involving several steps intended to quantify and communicate potential effects from local prevention activities. Based on a literature review, existing approaches are evaluated and subsequently discussed among stakeholders for determination of criteria for indicator and case-study selection, and finally communication of results. By means of LCA, the approach is applied on a range of cases, e.g. provision of drinking water in offices and electronic workstations in administration, and identifies potential impact reductions based on selected waste prevention measures. The study thereby demonstrates the importance of transparent involvement of stakeholders from scoping an LCA study to communicating the results.

\section{Concluding Thoughts}

While the LCA studies mentioned above may not offer conclusive solutions to all the challenges discussed in this editorial, these studies nevertheless represent important steps on the way to improved insight in methodological choices, more transparent LCA results, more robust and hopefully unbiased conclusions. In combination and individually, the studies also illustrate the considerable methodological challenges that still lie ahead of us within the field of waste LCA. We see the ongoing development of waste LCA as an important component of the work of industrial ecologists studying when and how to close resource loops. And we sincerely hope that the special feature provides both insight and inspiration for future research, paving the way for high quality and relevant decision-support for the benefit of society.

\section{References}

Abeliotis, K., A. Kalogeropoulos, and K. Lasaridi. 2012. Life Cycle Assessment of the MBT plant in Ano Liossia, Athens, Greece. Waste Management 32(1): 213-219. http://dx.doi.org/10.1016/j.wasman.2011.09.002.

Astrup, T.F., D. Tonini, R. Turconi, and A. Boldrin. 2015. Life cycle assessment of thermal Waste-to-Energy technologies: Review and recommendations. Waste Management 37: 104-115. http://dx.doi.org/10.1016/j.wasman.2014.06.011.

Bergsdal, H., A.H. Strømman, and E.G. Hertwich. 2005. Environmental Assessment of Two Waste Incineration Strategies for Central Norway. The International Journal of Life Cycle Assessment 10(4): 263-272. https://doi.org/10.1065/lca2005.04.204. 
Beylot, A., A. Hochar, P. Michel, M. Descat, Y. Ménard, and J. Villeneuve. 2017. Municipal Solid Waste Incineration in France: An Overview of Air Pollution Control Techniques, Emissions, and Energy Efficiency. Journal of Industrial Ecology 00(0): 1-11. http://doi.wiley.com/10.1111/jiec.12701.

Brogaard, L.K., A. Damgaard, M.B. Jensen, M. Barlaz, and T.H. Christensen. 2014. Evaluation of life cycle inventory data for recycling systems. Resources, Conservation and Recycling 87: 30-45.

Cadena, E., J. Colón, A. Artola, A. Sánchez, and X. Font. 2009. Environmental impact of two aerobic composting technologies using life cycle assessment. International Journal of Life Cycle Assessment 14(5): 401-410. https://doi.org/10.1007/s11367-009-0107-3.

Capobianco, O., G. Costa, and R. Baciocchi. 2017. Assessment of the Environmental Sustainability of a Treatment Aimed at Soil Reuse in a Brownfield Regeneration Context. Journal of Industrial Ecology 00(0): 1-12. https://doi.org/10.1111/jiec.12648.

Dolci, G., S. Nessi, L. Rigamonti, and M. Grosso. 2016. Life cycle assessment of waste prevention in the delivery of pasta, breakfast cereals, and rice. Integrated Environmental Assessment and Management 12(3): 445-458. https://doi.org/10.1002/ieam.1756.

Dormer, A., D.P. Finn, P. Ward, and J. Cullen. 2013. Carbon footprint analysis in plastics manufacturing. Journal of Cleaner Production 51: 133-141. http://dx.doi.org/10.1016/j.jclepro.2013.01.014.

EC. 2015a. COMMISSION STAFF WORKING DOCUMENT. Additional analysis to complement the impact assessment SWD (2014) 208 supporting the review of EU waste management targets. European Commission (EC). Brussels, Belgium.

EC. 2015b. Proposal for a directive of the European Parliament and of the Council amending Directive 2008/98/EC on waste, COM (2015) 595. European Commission (EC), Brussels, Belgium.

EEA. 2011. Earnings, jobs and innovation: the role of recycling in a green economy. European Environmental Agency (EEA), Copenhagen, Denmark(8): 28. http://www.eea.europa.eu/publications/earnings-jobs-and-innovation-the.

Ellen MacArthur Foundation. 2013. Towards the Circular Economy. Ellen MacArthur Foundation 1: 1-96. http://onlinelibrary.wiley.com/doi/10.1162/108819806775545321/abstract.

European Council. 2018. Waste management and recycling: Council adopts new rules. Press Release, 259/18, 22/05/2018. Brussels, Belgium. http://www.consilium.europa.eu/en/press/pressreleases/2018/05/22/waste-management-and-recycling-council-adopts-new-rules/.

Frosch, R.A. and N.E. Gallopoulos. 1989. Strategies for Manufacturing. Scientific American 261(3): 144-152. www.jstor.org/stable/24987406.

Gentil, E.C., D. Gallo, and T.H. Christensen. 2011. Environmental evaluation of municipal waste prevention. Waste Management 31(12): 2371-2379. http://dx.doi.org/10.1016/j.wasman.2011.07.030. 
Henriksen, T., T.F. Astrup, and A. Damgaard. 2017. Linking Data Choices and Context Specificity in Life Cycle Assessment of Waste Treatment Technologies: A Landfill Case Study. Journal of Industrial Ecology 00(0): 1-11. https://doi.org/10.1111/jiec.12709.

Hutner, P., D. Stindt, A. Thorenz, and A. Tuma. 2018. Transdisciplinary development of a life-cycle based approach to measure and communicate waste prevention effects in local authorities. Journal of Industrial Ecology: accepted for publication.

Laurent, A., J. Clavreul, A. Bernstad, I. Bakas, M. Niero, E. Gentil, T.H. Christensen, and M.Z. Hauschild. 2014. Review of LCA studies of solid waste management systems - Part II: Methodological guidance for a better practice. Waste Management 34(3): 589-606. http://dx.doi.org/10.1016/j.wasman.2013.12.004.

Nessi, S., L. Rigamonti, and M. Grosso. 2012. LCA of waste prevention activities: A case study for drinking water in Italy. Journal of Environmental Management 108: 73-83. http://dx.doi.org/10.1016/j.jenvman.2012.04.025.

Ortego, A., A. Valero, A. Valero, and E. Restrepo. 2018. Vehicles and Critical Raw Materials: A Sustainability Assessment Using Thermodynamic Rarity. Journal of Industrial Ecology 00(0): 1-11. http://doi.wiley.com/10.1111/jiec.12737.

RECREATE. 2017. STEPPING UP WASTE PREVENTION - CHALLENGES AND OPPORTUNITIES FOR. Policy brief no. 7, September 2017. Berlin/Brussels. http://www.recreatenet.eu/dweb/system/files/files/PolicyBriefs/RECREATE_PolicyBrief_no7.pdf.

Rigamonti, L., M. Grosso, and M. Giugliano. 2009a. Life cycle assessment for optimising the level of separated collection in integrated MSW management systems. Waste Management 29(2): 934-944. http://dx.doi.org/10.1016/j.wasman.2008.06.005.

Rigamonti, L., M. Grosso, and M.C. Sunseri. 2009b. Influence of assumptions about selection and recycling efficiencies on the LCA of integrated waste management systems. The International Journal of Life Cycle Assessment 14(5): 411-419. https://doi.org/10.1007/s11367-009-0095-3.

Ripa, M., G. Fiorentino, V. Vacca, and S. Ulgiati. 2017. The relevance of site-specific data in Life Cycle Assessment (LCA). The case of the municipal solid waste management in the metropolitan city of Naples (Italy). Journal of Cleaner Production 142: 445-460. http://dx.doi.org/10.1016/j.jclepro.2016.09.149.

Sevigné-Itoiz, E., C.M. Gasol, J. Rieradevall, and X. Gabarrell. 2015. Contribution of plastic waste recovery to greenhouse gas (GHG) savings in Spain. Waste Management 46: 557-567. https://doi.org/10.1016/j.wasman.2015.08.007.

Shen, L., E. Worrell, and M.K. Patel. 2010. Open-loop recycling: A LCA case study of PET bottle-to-fibre 
recycling. Resources, Conservation and Recycling 55(1): 34-52.

http://dx.doi.org/10.1016/j.resconrec.2010.06.014.

Tonini, D., P.F. Albizzati, and T.F. Astrup. 2018. Environmental impacts of food waste: Learnings and challenges from a case study on UK. Waste Management 76: 744-766. https://doi.org/10.1016/j.wasman.2018.03.032.

Vadenbo, C., S. Hellweg, and T.F. Astrup. 2017. Let's Be Clear(er) about Substitution: A Reporting Framework to Account for Product Displacement in Life Cycle Assessment. Journal of Industrial Ecology 21(5): 1078-1089. https://doi.org/10.1111/jiec.12519.

Vadenbo, C., S. Hellweg, and G. Guillén-Gosálbez. 2014. Multi-objective optimization of waste and resource management in industrial networks - Part I: Model description. Resources, Conservation and Recycling 89: 52-63. https://doi.org/10.1016/j.resconrec.2014.05.010.

Villanueva, A. and H. Wenzel. 2007. Paper waste - recycling, incineration or landfilling? A review of existing life cycle assessments. Waste Management (New York, N.Y.) 27(8): S29-46. http://dx.doi.org/10.1016/j.wasman.2007.02.019.

WRAP. 2010. Environmental benefits of recycling - 2010 update. Waste \& Resource Action Program (WRAP). Banbury, UK.

Zink, T. and R. Geyer. 2017. Circular Economy Rebound. Journal of Industrial Ecology 21(3): 593-602. https://doi.org/10.1111/jiec.12545.

Zink, T., R. Geyer, and R. Startz. 2016. A Market-Based Framework for Quantifying Displaced Production from Recycling or Reuse. Journal of Industrial Ecology 20(4): 719-729.

https://doi.org/10.1111/jiec.12317. 